\title{
EFEKTIVITAS MINYAK SEREH TERHADAP LARVA Anopheles Sp.
}

\section{Tusy Triwahyuni ${ }^{1}$, Ismalia Husna ${ }^{1}$, Robi Azis ${ }^{2}$, Ni Gusti Ayu Dewi Rismasari ${ }^{2}$, Fadila Dwinda Fitriyani²}

\author{
${ }^{1}$ Departemen Parasitologi, Fakultas Kedokteran, Universitas Malahayati \\ ${ }^{2}$ Program Studi Kedokteran, Fakultas Kedokteran, Universitas Malahayati
}

[email Korespondensi: tussythree@gmail.com]

\begin{abstract}
Effectiveness Of Lemongrass Oil Towards Anopheles sp Larvae. Malaria is a life-threatening disease caused by the parasite Protozoa genus Plasmodium. The disease is transmitted to humans through the bite of Anopheles female species which act as vectors. Lampung Province is included in low endemicity with an annual API of 0.4 per 1,000 population. Even though in Lampung Province the endemicity is low, some areas in Lampung Province are endemic areas that have the potential to develop malaria. Malaria endemic villages in Lampung Province amount to 223 villages or $10 \mathrm{ml}$ of all villages. API in the Regency / City in 2014 was highest in Bandar Lampung City and Pesawaran Regency (Padang Cermin Village, Pidada Village and Hanura Village). To determine the effectiveness of lemongrass oil effectiveness against larvae of Anopheles sp. Laboratory experimental research type, Completely Randomized Design with treatment in the experimental group with the control group. This design consisted of two groups, each randomly selected (randomization). This study used 5 treatments consisting of 4 treatment groups and 1 control group (negative control) with 5 replications (replication). After doing this research, the results of lemongrass oil had the effectiveness of larvae death at a concentration of $0.4 \mathrm{ml}$ of dead larvae in the previous study at a concentration of $0.42 \mathrm{ml}$ to kill larvae within 2 hours. And the highest average at $1 \mathrm{ml}$ concentration, the larvae died $100 \mathrm{ml}$. This study used citronella oil mixed with tween $80 \mathrm{ml}$ and $198 \mathrm{ml}$ aquades and a variety of concentrations could kill the larvae within 2 hours the larvae died $100 \mathrm{ml}$ because the citronella oil contained contact poison so that the larvae lose fluid continuously so that the larvae lacking fluids usually caused death in the larvae. After conducting research, the results of lemongrass oil have an effectiveness against the death of Anopheles Sp larvae.
\end{abstract}

Keywords : Lemongrass Oil, Anopheles sp., Larvae, Malaria

Abstrak: Efektivitas Minyak Sereh Terhadap Larva Anopheles Sp. Malaria
adalah penyakit mengancam jiwa yang disebabkan oleh parasit Protozoa genus
Plasmodium. Penyakit ini ditularkan ke manusia melalui gigitan nyamuk Anopheles
spesies betina yang bertindak sebagai vektor. Provinsi Lampung termasuk dalam
endemisitas rendah dengan API per tahun 0,4 per 1.000 penduduk. Walaupun di
Provinsi Lampung endemisitas rendah, tetapi sebagian daerah di Provinsi Lampung
merupakan daerah endemis yang berpotensi untuk mengembangkan penyakit
malaria. Desa endemis malaria di Provinsi Lampung berjumlah 223 desa atau $10 \mathrm{ml}$
dari seluruh jumlah desa. API di Kabupaten/Kota pada tahun 2014 tertinggi berada
di Kota Bandar Lampung dan Kabupaten Pesawaran (Desa Padang Cermin, Desa
Pidada dan Desa Hanura). Untuk mengetahui keefektifan efektivitas minyak sereh
terhadap daya tahan larva Anopheles sp. Jenis penelitian eksperimental
laboratorium, Rancangan penelitian Acak Lengkap dengan perlakuan pada kelompok
eksperimen dengan kelompok kontrol. Desain ini terdapat dua kelompok masing-
masing dipilih secara acak (randomization). Penelitian ini menggunakan 5 perlakuan
yang terdiri dari 4 kelompok perlakuan dan 1 kelompok kontrol ( kontrol negatif ) 
dengan 5 kali ulangan ( replikasi ). Setelah di lakukan penelitian ini di dapatkan hasil minyak sereh memiliki efektivitas terhadap kematian larva pada konsentrasi $0,4 \mathrm{ml}$ larva mati sama penelitian sebelumnya pada konsentrasi $0,42 \mathrm{ml}$ membunuh larva pada waktu 2 jam. dan rata-rata tertinggi pada konsentrasi $1 \mathrm{ml}$ itu larva mati $100 \mathrm{ml}$. Penelitian ini menggunakan minyak sereh dicampur tween $80 \mathrm{ml}$ dan aquades $198 \mathrm{ml}$ dan berbagai konsentrasi bisa membunuh larva pada waktu 2 jam larva mati $100 \mathrm{ml}$ karena minyak sereh mengandung racun kontak sehingga larva kehilangan cairan terus menerus sehingga larva kekurangan cairan biasa menyebabkan kematian pada larva. Setelah dilakukan penelitian didapatkan hasil minyak sereh memiliki efektivitas terhadap kematian larva Anopheles Sp.

Kata Kunci : Minyak Sereh, Larva Anopheles Sp., Malaria

\section{PENDAHULUAN}

Malaria adalah penyakit mengancam jiwa yang disebabkan oleh parasit Protozoa genus Plasmodium. Penyakit ini ditularkan ke manusia melalui gigitan nyamuk Anopheles $s p$. betina yang bertindak sebagai vektor. Ada lima spesies Plasmodium sp. yaitu, Plasmodium falciparum, Plasmodium vivax, Plasmodium ovale, Plasmodium malariae, dan plasmodium knowlesi (Soedarto, 2011; Kementrian Kesehatan RI, 2015). Malaria dalam Rencana Strategis (Renstra) Kementerian Kesehatan Tahun 2015-2019 dalam Keputusan Menteri kesehatan Republik Indonesia Nomor Hk. 02.02/Menkes/52/2015 masih menjadi prioritas kesehatan setelah HIV/ AIDS dan Tuberculosis untuk kategori penyakit menular. Secara umum kasus malaria tahun 2005-2012 cenderung menurun. Target pada Rencana Strategis (Renstra) periode 2010-2011, diupayakan API mengalami penurunan hingga 1 kasus per 1000 penduduk pada tahun 2014. Tahun 2009 API sebesar 1,85\%, menurun menjadi $1,75 \%$ tahun 2011 , dan terus menurun menjadi $1,38 \%$ pada tahun 2013 mendekati target $1 \%$ pada 2014 (Kemenkes, 2015).

Provinsi Lampung termasuk dalam endemisitas rendah dengan API per tahun 0,4 per 1.000 penduduk. Walaupun di Provinsi Lampung endemisitas rendah, tetapi sebagian daerah di Provinsi Lampung merupakan daerah endemis yang berpotensi untuk mengembangkan penyakit malaria. Desa endemis malaria di Provinsi Lampung berjumlah 223 desa atau $10 \%$ dari seluruh jumlah desa. API di Kabupaten/Kota pada tahun 2014 tertinggi berada di Kota Bandar Lampung dan Kabupaten Pesawaran (Desa Padang Cermin, Desa Pidada dan Desa Hanura) (Dinas Kesehatan Provinsi Lampung, 2014).

Perubahan lingkungan global/ iklim terdiri dari temperatur/ suhu dan pola tiupan angin yang mempunyai dampak langsung pada reproduksi vektor, perkembangannya, umur, dan perkembangan parasit dalam tubuh vektor Perubahan lingkungan fisik yang mempengaruhi banyaknya jumlah vektor malaria seperti danau, kolam ikan, muara sungai, waduk, tambak udang, sawah, irigasi, saluran pembuangan air, dan lubang bekas galian (Nurmaulina,2017)

Insektisida adalah bahan yang mengandung senyawa kimia yang digunakan untuk membunuh serangga (Parasitologi UI, 2008). Temefos sebagai salah satu insektisida kelompok organofosfat, merupakan larvasida yang paling luas digunakan, karena dalam bentuk butiran dapat mengendalikan populasi nyamuk langsung di tempat perkembangbiakannya (Mara Ipa dkk, 2017). Larvasida ini tidak toksik terhadap mamalia termasuk manusia, tetapi mempunyai toksisitas tinggi terhadap larva nyamuk (Parasitologi UI, 2008).

Tanaman zodia merupakan tanaman yang berasal dari Papua yang berfungsi untuk mengusir nyamuk, tanaman zodia ini dapat menurunkan 
kasus malaria. Pemanfaatan tanaman tersebut ditargetkan pada akhir Tahun 2017 semua rumah telah dipagari oleh tanaman pengusir nyamuk. Daun zodia mengandung zat linanool dan a-pinene yang sangat tidak disukai nyamuk. Bentuk dan warna tanaman zodia tidak kalah cantiknya dengan bunga Geranium. tanaman asli Indonesia ini menjadi andalan penduduk untuk mengusir nyamuk. Selain zodia, ada pula beberapa tanaman lain yang mampu mengusir nyamuk, di antarnya lavender, tapak dara, marygold, sereh, kemangi, dan kecombrang (Kemenkes,2017).

Minyak sereh (Cymbopogon citratus) merupakan salah satu tanaman yang berpotensi sebagai insektisida. Batang dan daun sereh digunakan untuk memasak, minyak wangi, bahan pencampur jamu, dan juga dibuat minyak sereh Pada sereh (Cymbopogon citratus) terkandung senyawa sitronela yang mempunyai sifat racun, menurut cara kerjanya racun ini seperti racun kontak yang dapat memberikan kematian karena kehilangan cairan secara terus menerus sehingga tubuh nyamuk kekurangan cairan. Ramuan sereh dapat dipergunakan sebagai pengusir nyamuk, dengan proses pembuatan yang sederhana, tidak mengeluarkan biaya tinggi, dan alamiah (Ameliana Pratiwi,2012). Sereh wangi (Cymbopogon citraturs) merupakan salah satu tanaman yang memiliki banyak manfaat. Hasil penyulingan daun dan batang sereh diperoleh minyak sereh wangi yang dalam dunia perdagangan dikenal dengan nama Citronella Oil.

Pada penelitian Yulianis dkk, tahun 2018 yang berjudul "Uji efektivitas anti nyamuk minyak sereh sereh dapur dalam bentuk semprot menyebutkan bahwa Variasi konsentrasi minyak sereh daun dapur (Cymbopogon citratus) berpengaruh terhadap aktivitasnya dalam membunuh nyamuk semakin besar konsentrasi minyak sereh daun sereh dapur (Cymbopgon citratus) maka aktivitas membunuh nyamuk semakin tinggi. Berdasarkan latar belakang di atas, maka peneliti ingin mengetahui "Efektivitas minyak sereh terhadap daya tahan larva Anopheles sp.

\section{METODE}

Tipe penelitian yang digunakan adalah penelitian eksperimental laboratorium. Desain penelitian yang digunakan Rancangan Acak Lengkap yaitu jenis penelitian rancangan paling sederhana dari beberapa macam perancangan yang baku. Rancangan ini dipergunakan jika ingin mempelajari pengaruh beberapa perlakuan dengan sejumlah ulangan untuk menjadi satuansatuan percobaan. Dalam desain ini terdapat dua kelompok masing-masing dipilih secara acak (randomization). Desain penelitian ini mengukur pengaruh perlakuan pada kelompok eksperimen dengan cara membandingkan kelompok tersebut dengan kelompok kontrol (Riyanto, 2011)

Di dalam penelitian ini, menggunakan 5 perlakuan yang terdiri dari 4 kelompok perlakuan dan 1 kelompok kontrol ( kontrol negatif ) dengan 5 kali ulangan ( replikasi ). Jumlah larva semua kelompok uji secara keseluruhan adalah 500 larva. Alat-alat yang digunakan dalam penelitian ini adalah cidukan untuk mengambil larva Anopheles sp. yang ada di dalam genangan air. Bahan yang digunakan adalah Minyak sereh, dan larva Anopheles sp. Pengamatan dilakukan sampai 120 menit pada pengamatan jam 1 dan ke 2 setelah perlakuan sesuai dengan standar WHO, yaitu mengenai standar penelitian pada serangga. Tunggu hingga semua larva mati. Hitung dan catat berapa lama larva mati. Kematian larva dapat diamati secara fisik dengan tanda-tanda antara lain: larva tidak bergerak sama sekali walaupun telah mendapat rangsangan berupa 
sentuhan maupun hembusan angin serta tubuh nyamuk telah menunjukkan kekakuan. Apabila jumlah kematian larva pada kontrol negatif kurang dari 5\%, maka hal tersebut dapat diabaikan, namun apabila lebih dari $20 \%$ maka uji harus diulang. Perlakuan terhadap sampel uji dilakukan sebanyak 5 kali replikasi.

Setelah diperoleh data jumlah larva Anopheles sp. yang mati, maka dilakukan pengolahan dan analisis data. Pengolahan data adalah suatu proses untuk memperoleh data ringkasan atau angka ringkasan dengan cara-cara atau rumus-rumus tertentu. Dilakukan editing dan tabulating data. Data selanjutnya dianalisis dengan melakukan uji statistik menggunakan program statistik komputer SPSS dan Microsoft Excel.

\section{HASIL}

Berdasarkan data pada tabel 1 menunjukkan bahwa jumlah rata- rata tertinggi larva uji yang mati dalam waktu 2 jam setelah perlakuan minyak sereh pada konsentrasi $1 \mathrm{ml}$ ppm yaitu sebanyak 20 larva uji yang mati.

Tabel 1. Data Jumlah Larva Anopheles sp. yang Mati setelah Dipaparkan oleh minyak sereh (Cympogon cytratus) dalam berbagai konsentrasi

\begin{tabular}{|c|c|c|c|c|c|c|c|c|}
\hline \multirow{2}{*}{$\begin{array}{c}\text { Konsentrasi } \\
(\mathrm{ml})\end{array}$} & \multirow[t]{2}{*}{ Pengulangan } & \multirow{2}{*}{$\begin{array}{l}\text { Jumlah } \\
\text { Larva }\end{array}$} & \multicolumn{6}{|c|}{$\begin{array}{l}\text { Jumlah larva yang mati dalam } \\
\text { waktu (menit) }\end{array}$} \\
\hline & & & 5 & 10 & 20 & 40 & 60 & 120 \\
\hline \multirow{5}{*}{0} & 1 & \multirow{5}{*}{20} & 0 & 0 & 0 & 0 & 0 & 0 \\
\hline & 2 & & 0 & 0 & 0 & 0 & 0 & 0 \\
\hline & 3 & & 0 & 0 & 0 & 0 & 0 & 0 \\
\hline & 4 & & 0 & 0 & 0 & 0 & 0 & 0 \\
\hline & 5 & & 0 & 0 & 0 & 0 & 0 & 0 \\
\hline \multirow{5}{*}{0,4} & 1 & \multirow{5}{*}{20} & 0 & 4 & 7 & 11 & 15 & 20 \\
\hline & 2 & & 0 & 4 & 7 & 11 & 15 & 15 \\
\hline & 3 & & 0 & 4 & 7 & 11 & 15 & 15 \\
\hline & 4 & & 0 & 4 & 7 & 11 & 15 & 15 \\
\hline & 5 & & 0 & 4 & 7 & 11 & 15 & 15 \\
\hline \multirow{5}{*}{0,6} & 1 & \multirow{5}{*}{20} & 3 & 5 & 8 & 12 & 17 & 20 \\
\hline & 2 & & 3 & 5 & 8 & 12 & 18 & 20 \\
\hline & 3 & & 3 & 5 & 8 & 13 & 17 & 20 \\
\hline & 4 & & 3 & 5 & 8 & 13 & 17 & 20 \\
\hline & 5 & & 3 & 5 & 8 & 13 & 17 & 20 \\
\hline \multirow{5}{*}{0,8} & 1 & \multirow{5}{*}{20} & 7 & 8 & 8 & 13 & 17 & 20 \\
\hline & 2 & & 7 & 8 & 8 & 13 & 18 & 20 \\
\hline & 3 & & 7 & 8 & 9 & 12 & 19 & 20 \\
\hline & 4 & & 7 & 8 & 9 & 14 & 19 & 20 \\
\hline & 5 & & 7 & 8 & 8 & 15 & 19 & 20 \\
\hline \multirow{5}{*}{1} & 1 & \multirow{5}{*}{20} & 20 & 20 & 20 & 20 & 20 & 20 \\
\hline & 2 & & 20 & 20 & 20 & 20 & 20 & 20 \\
\hline & 3 & & 20 & 20 & 20 & 20 & 20 & 20 \\
\hline & 4 & & 20 & 20 & 20 & 20 & 20 & 20 \\
\hline & 5 & & 20 & 20 & 20 & 20 & 20 & 20 \\
\hline
\end{tabular}


Tabel 2. Data Jumlah Larva Anopheles sp. yang Mati setelah Dipaparkan oleh minyak sereh perwaktu (Cympogon cytratus) dalam persentase mortalitas

\begin{tabular}{ccccccc}
\hline \multirow{2}{*}{$\begin{array}{c}\text { Konsentrasi } \\
(\mathbf{m l})\end{array}$} & \multicolumn{7}{c}{$\begin{array}{c}\text { Persentase mortalitas dalam } \\
\text { waktu }\end{array}$} & $\mathbf{5}$ & $\mathbf{1 0}$ & $\mathbf{2 0}$ & $\mathbf{4 0}$ & $\mathbf{6 0}$ & $\mathbf{1 2 0}$ \\
\cline { 2 - 7 } & 0 & 0 & 0 & 0 & 0 & 0 \\
\hline 0 & 0 & 4 & 8 & 11 & 15 & 100 \\
\hline 0,4 & 3 & 5 & 8 & 12 & 17 & 100 \\
\hline 0,6 & 8 & 8 & 8 & 18 & 13 & 100 \\
\hline 0,8 & 100 & 100 & 100 & 100 & 100 & 100 \\
\hline 1 & \multicolumn{10}{c}{}
\end{tabular}

Pada bentuk persentase mortalitas rata tertinggi jumlah larva yang mati bahwa jumlah larva yang sudah di pada konsentrasi $1 \mathrm{ml}$ larva mati $100 \mathrm{ml}$. gunakan 50 larva yang diujikan dan rata-

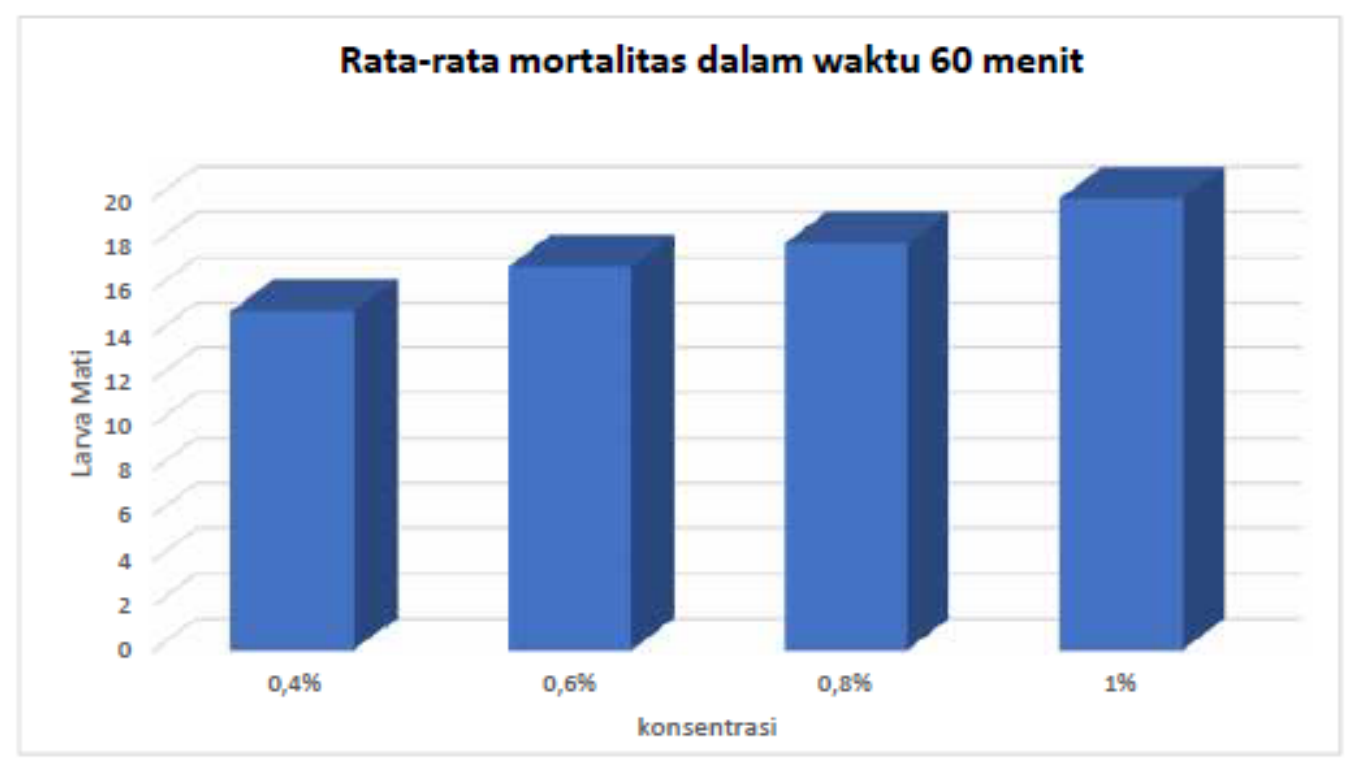

\section{Gambar 1. Hasil Rata-Rata Mortalitas Larva Anopheles sp. dengan Minyak Sereh (Cympogon citratus)}

Berdasarkan data pada gambar 1 menunjukkan bahwa dalam rentang waktu 60 menit jumlah larva uji yang mati setelah perlakuan konsentrasi $0,4 \mathrm{ml}$ minyak sereh yaitu 15 larva, $0,6 \mathrm{ml}$ minyak sereh yaitu 17 larva uji yang mati. Dalam rentang waktu 40 menit dengan konsentrasi $0,8 \mathrm{ml}$ minyak sereh yaitu larva uji yang mati dalam rentang waktu 40 menit. Dan pada konsentrasi $1 \mathrm{ml}$ minyak sereh yaitu 20 larva uji yang mati. Jumlah rata- rata tertinggi larva uji yang mati dalam waktu 2 jam setelah perlakuan minyak sereh pada konsentrasi $1 \mathrm{ml}$ ppm yaitu sebanyak 20 larva uji yang mati. Jumlah rata- rata tertinggi larva uji yang mati dalam waktu 60 menit setelah perlakuan terdapat 
pada konsentrasi $0,4 \mathrm{ml}$ terdapat 15 larva yang mati dan pada konsentrasi $0,6 \mathrm{ml} 17$ larva yang mati, pada konsentrasi $0,8 \mathrm{ml}$ 18 larva yang mati dan $1 \mathrm{ml}$ sebanyak 20 larva uji yang mati jadi rata-rata jumlah larva yang mati $100 \mathrm{ml}$ pada konsentrasi $1 \mathrm{ml}$.

Tabel 3. Uji Anova

\begin{tabular}{ccccc}
\hline Waktu & $\mathbf{N}$ & $\begin{array}{c}\text { Konsentrasi } \\
(\mathbf{m l})\end{array}$ & Rata-rata & P value \\
\hline \multirow{2}{*}{2} & 20 & 0,4 & 15,00 & \\
& 20 & 0,6 & 17,20 & \multirow{2}{*}{0} \\
\cline { 2 - 4 } & 20 & 0,8 & 18,40 & \\
\cline { 2 - 4 } & 20 & 1 & 20,00 & \\
\hline
\end{tabular}

Berdasarkan tabel 3 hasil perhitungan di atas dapat diketahui bahwa pada minyak sereh (Cymbopogon citratus) selama 24 jam dengan konsentrasi $1 \mathrm{ml}$ lebih tinggi di bandingkan pada $0,4 \mathrm{ml}, 0,6 \mathrm{ml}$ dan $0,8 \mathrm{ml}$ Hal ini ditunjukkan dengan nilai rata-rata minyak sereh (Cymbopogon citrats) dengan konsentrasi $1 \mathrm{ml}$ yaitu sebesar 20,00 dan konsentrasi pada minyak sereh (Cymbopogon citratus) yang lebih rendah yaitu konsentrasi $0,4 \mathrm{ml}$. Pada Uji Post Hoc jumlah kematian pada nyamuk nilai signifikan $(5,0)$ pada konsentrasi $1 \mathrm{ml}$ tidak mempunyai perbedaan yang di signifikan $(5,0)$ dengan konsentrasi 0,4 $\mathrm{ml}$ tetapi mempunyai perbedaan nilai rata-rata yang di signifikan dengan konsentrasi $0,6 \mathrm{ml}$ dan $0,8 \mathrm{ml}$ dengan probabilitas 0,00 konsentrasi $0,4 \mathrm{ml}$ tidak mempunyai perbedaan yang di signifikan dengan konsentrasi $1 \mathrm{ml}(5,0)$

Tabel 4. Analisis Probit

\begin{tabular}{cccc|c}
\hline \multirow{2}{*}{$\begin{array}{c}\text { Mortalitas } \\
\text { MI }\end{array}$} & \multirow{2}{*}{ Konsentrasi } & \multirow{2}{*}{$\begin{array}{c}\text { Tingkat } \\
\text { Kepercayaan }\end{array}$} & \multicolumn{2}{c}{ Interval Kepercayaan } \\
\cline { 5 - 6 } & & Batas bawah & Batas atas \\
\hline 50 & 0,264 & 95 & 0,774 & 0,480 \\
\hline
\end{tabular}

Untuk mengetahui yang dapat menyebabkan mortalitas larva hingga $50 \mathrm{ml}$ selama 2 jam, maka dilakukan uji SPSS 2.2. dari hasil perhitungan di

\section{PEMBAHASAN}

Setelah dilakukan penelitian ini didapatkan hasil minyak sereh memiliki efektivitas terhadap kematian larva pada konsentrasi $0,4 \mathrm{ml}$, hal ini sama penelitian sebelumnya pada konsentrasi $0,42 \mathrm{ml}$ membunuh larva pada waktu 2 jam. Rata-rata tertinggi larva mati pada konsentrasi $1 \mathrm{ml}$ sebesar $100 \%$. Penelitian ini menggunakan minyak sereh dicampur tween $801 \mathrm{ml}$ dan aquades $198 \mathrm{ml}$. Diketahui berbagai dapatkan LC50 yang di dapatkan adalah 0,264 ml Penentuan nilai LC50 dilakukan untuk pengembangan lebih lanjut penggunaan bahan.

konsentrasi minyak sereh bisa membunuh larva pada waktu 2 jam sebesar $100 \%$ karena minyak sereh mengandung racun kontak sehingga larva kehilangan cairan terus menerus sehingga larva kekurangan cairan biasa menyebabkan kematian pada larva.

Tween 80 merupakan surfaktan non-ionik berwujud cair, berwarna kekuningan, berminyak, dan larut dalam air. Tween 80 di gunakan sebagai peningkat kelarutan (Galih 
suhardi,2015). Dengan penambahan Tween 80 relatif lebih encer karena Tween 80 sifatnya mudah larut dalam air sehingga larutan menjadi lebih encer dan lekat menjadi lebih kecil (Srirahayu 2015). Tingkat konsentrasi yang menyebabkan keracunan ditentukan dengan letal konsentrasi 50 (LC50). LC50 adalah konsentrasi dari suatu bahan yang menyebabkan $50 \%$ populasi mengalami kematian. LC50 dapat digunakan untuk menentukan toksisitas dari suatu zat (Andriani, 2008). Perhitungan nilai LC50 yang di dapatkan adalah $0,264 \mathrm{ml}$ yang menyebabkan populasi $50 \%$ kematian pada larva, hal ini sama penelitian sebelumnya nilai LC50 yang di dapatkan 0,39 ppm. Penelitian ini dilakukan untuk mengetahui efektivitas minyak sereh (Cymbopogon citratus) terhadap daya tahan larva Anopheles sp. Minyak sereh mengandung senyawa sitronela yang mempunyai sifat racun kontak. Cara kerja racun ini dapat memberikan kematian karena larva kehilangan cairan secara terus menerus (Yulianis, dkk 2018).

Menurut Wardani (2009), kandungan dari sereh terutama minyak sereh/dengan komponen sitronela 32$45 \mathrm{ml}$, geraniol $12-18 \mathrm{ml}$, sitronelol 11 $15 \mathrm{ml}$, geranilasetat $3-8 \mathrm{ml}$, sitronelilasetat 2-4ml, sitral, kavikol, eugenol, elemol, kadinol, kadinen, vanilin, limonen, kamfen. Minyak Sereh mengandung 3 komponen utama yaitu sitronelal, sitronelol dan geraniol (Sastrohamidjojo, 2004). Hasil penyulingan dari Andropogon nardusL dapat diperoleh minyaksereh yang disebut Oleum citronellae, terutama terdiri atas geraniol dan sitronelal yang dapat digunakan untuk menghalau nyamuk (Tjitrosoepomo, 2005). Abu dari daun dan tangkai sereh mengandung 45 $\mathrm{ml}$ silika yang merupakan penyebab desikasi (keluarnya cairan tubuh secara terus menerus) pada kulit serangga sehingga serangga akan mati kekeringan. Sitronelol dan geraniol merupakan bahan aktif yang tidak disukai dan sangat di hindari serangga, termasuk nyamuk sehingga penggunaan bahan-bahan ini sangat bermanfaat sebagai bahan pengusir nyamuk (Yunus, 2008). Berdasarkan data pada tabel 4.1 dapat dilihat bahwa jumlah larva uji yang mati setelah perlakuan konsentrasi $0,4 \mathrm{ml}, 0,6 \mathrm{ml}$.dan $0,8 \mathrm{ml}$ minyak sereh dalam waktu 120 menit yaitu 20 larva uji yang mati. Dan konsentrasi paling efektif pada konsentrasi $1 \mathrm{ml}$ dalam waktu 5 menit larva mati $100 \%$. Hasil pada penelitian ini sesuai dengan penelitian yang di lakukan oleh Syarif,H pada tahun 2014 yang berjudul "Efektivitas Minyak Sereh dapur (Cymbogon citratus) Sebagai Larvasida pada Nyamuk Aedes Sp" didapatkan kematian pada Aedes aegypti sebesar $100 \%$ pada konsentrasi 420 ppm, 652 ppm, 1250 ppm, 2500 ppm, pada kelompok yang menjadi kontrol, tidak dapat kematian pada larva. Kematian larva di temukan pada satu jam pertama. Berdasarkan tabel 4.3 pada analisis Anova nilai yang di signifikan 0.000, hal ini di tunjukan bahwa jumlah kematian larva dengan konsentrasi $1 \mathrm{ml}$ yaitu sebesar 20,00 dan di bandingkan pada konsentrasi $0,4 \mathrm{ml}$ yang paling rendah sebesar 15,00 , Bisa di lihat dari tabel 4.4 pada analisis Post Hoc nilai yang di signifikan yaitu 0,000.karena nilai signifikan berbagi konsentrasi bisa berpengaruh terhadap kematian larva 100\%.

\section{KESIMPULAN}

Minyak sereh efektif karena mengandung racun kontak sehingga larva kehilangan cairan terus menerus sehingga larva kekurangan cairan biasa menyebabkan kematian pada larva. Rata-rata kematian larva dari yang tinggi sampai yang rendah itu semakin kecil kematian pada larva. Dalam berbagai konsentrasi minyak sereh, konsentrasi paling efektif yaitu $1 \mathrm{ml}$ dalam waktu 2 jam larva sudah mati. Nilai LC50 yang di dapatkan adalah 0,264 ml. Saran untuk penelitian selanjutnya diharapkan dapat melakukan penelitian tentang efektivitas 
minyak sereh terhadap populasi Anopheles sp. dan perlu diketahui penelitian lebih lanjut tentang metode lain dalam isolasi minyak sereh dan diharapkan untuk melakukan penelitian selanjutnya dalam konsentrasi $<1 \mathrm{ml} /$ $>0,4 \mathrm{ml}$.

\section{DAFTAR PUSTAKA}

Adnyana. (2011). Beberapa Aspek Bionomik Anopheles Sp Di Kabupaten Sumba Tengah, Provinsi Nusa Tenggara Timur. Nusa Tenggara Timur. Media Litbang Kesehatan 21 (2).

Andriani, A. (2008). Uji Potensi Larvasida Fraksi Ekstrak Daun Clinacanthus nutans L. Terhadap Larva Instar III Nyamuk Aedes aegypti. [Skripsi]. Bogor: Institut Pertanian Bogor.

Dinas Kesehatan Kabupaten Pesawaran. (2015). Profil Dinkes Kabupaten Pesawaran tahun 2014.

Heodarjo, dkk. (2008). Vektor Penyakit Protozoa. Jakarta: Fakultas Kedokteran Universitas Indonesia. Ed.IV.

Ihsan, T, dkk. (2018). Uji Toksisitas Akut dalam Penentuan LC50-96h Insektisida Klorpirifos terhadap Dua Jenis Ikan Budidaya Danau. Jurnal Ilmu Lingkungan 11(1).

Lucia,W. (2015). Isolasi Sitronellal Dari Minyak Sereh Wangi (Cymbopogon winterinasus Jowit) Dengan Distilasi Fraksinasi Peratutan Tekanan. Jurnal Farmasin Saints dan Komunitas 12(1).

Kementerian Kesehatan RI. (2015). Rencana Strategis Kementerian Kesehatan. Jakarta: Kemenkes.

Kementrian Kesehatan RI. (2017). Tanaman Zodiac Pengusir Nyamuk. Jakarta: Kemenkes.

Nurhadi, G. (2015). Pengaruh Konsentrasi Tween 80 Terhadap Stabilitas Fisik Obat Kumur Minyak Astiri Herba Kemangi (Ocinum americanum.L). Jakarta. Nurmaelina, Wage. (2017). Hubungan Pengetahuan, Sikap dan Perilaku
Falcifarum dengan derajat infeksi di wilayah kerja Puskesmas Hamura Kecamatan Teluk Pandan Kabupaten Pesawaran Provinsi Bandar Lampung. Lampung: Universitas Lampung.

Pratiwi. (2012). Penerimaan Masyarakat Terhadap Larvasida Alami. Jurnal Kesehatan Masyarakat 8 (1).

Putra, T.R.I. (2011). Malaria dan Permasalahannya. Jurnal Kedokteran Syiah Kuala 11(2).

Rinidar. (2010). Pemodelan Kontrol Malaria Melalui Pengelolaan Teintergrasi Di Kemukiman Lamteube, Naggroe Aceh Darusssalam. [Disertasi]. Medan: Sekolah Pascasarjana Program Doktor Universitas Utara Medan.

Sastriawan. (2014). Efektivitas Serai Dapur Sebagai Larvasida Pada Larva Nyamuk Aedes sp. Jakarta: Universitas Islam Negri Syarif Hidayatullah Jakarta.

Safar. (2010). Parasitiologi Kedokteran Protozoologi, Helmintologi, Entomologi. Bandung: Yrma Widya.

Sri, R. (2015). Pengunaan Tween 80 Sebagai Sufaktan Dalam Formulasi Mikroemulsi Minyak Astiri Daun Jeruk Sambal (Citrus microcarpa Bunge) Dan Uji Aktivitas Terhadap Propinibacterium Acnes Universitas Tangjungpura Pontianak

Solikhah. (2009). Pola Penyebaran Penyakit Malaria Di Kecamatan Kokap Kabupaten Kulon Progo DIY. Yogyakarta: Universitas Ahmad Dahlan.

Sutanto I., dkk. (2008). Parasitologi Kedokteran Edisi IV. Jakarta: Fakultas Kedokteran UI.

Yulianis. (2018). Uji Aktivitas Anti Nyamuk Minyak Astiri Sereh Dapur Dalam Bentuk Semprot. Jurnal Ipteks Terapan Vol.12 No. 1. Padang: Universitas Andalas Padang. 
WHO. (2017). World Malaria Report 2017. Leuxembourg: WHO. 